\title{
Composite material based on the polyethylene terephthalate polymer and modified fly ash filler
}

\author{
Nikolai Zaichenko ${ }^{1}$, and Vladislav Nefedov ${ }^{1 *}$ \\ ${ }^{1}$ Donbas National Academy of Civil Engineering and Architecture, Donetsk region, 283186, Ukraine
}

\begin{abstract}
The possibility of filling the recycled polyethylene terephthalate (rPET) with fly ash was studied to make a polymer composite material (PCM). It is shown that high adhesion between polymeric matrix and mineral filler is the key parameter to produce high performance PCM. For this purpose the acid-basic interaction as well as the thermodynamic work of adhesion between components of PCM were calculated. The technique of modifying fly ash filler with $5 \%$ concentration solution of sulfuric acid to increase acid-basic interaction has been elaborated. The resulting behavioral patterns are listed and compared to those of composites containing untreated fly ash particles.
\end{abstract}

\section{Introduction}

Disposal of waste materials from different types of industry has become an actual problem. To solve this problem, two generalized routes come to mind: firstly, to reuse the disposed materials as received in some suitable applications, and secondly to recycle the waste in order to obtain a new material that may again find application in the parent or in another industry [1-4]. For instance, waste polyethylene terephthalate (PET) plastic is neither environmentally biodegradable nor compostable, which creates disposal problems. Recycling has emerged as the most practical method to deal with this problem, especially with products such as rPET beverage bottles [5]. It is well known that melted rPET material can be molded, extruded or otherwise formed to shape a variety of articles, e.g. building materials and products.

On the other hand the reinforcing effect of mineral fillers for polymers has been recognized since the last few decades. Improving the mechanical, electrical, thermal, optical and processing properties of the polymer with the addition of filler materials has become a very popular research interest to make a composite material [6], which can be defined as a combination of two or more materials that results in better properties than those of the individual components used alone [7]. The two constituents are a reinforcement and a matrix. The main advantages of composite materials are their high strength and stiffness, improved fatigue life, corrosion resistance, combined with low density, when compared with bulk materials, allowing for a weight reduction in the finished part $[8,9]$.

Developing low-cost composite materials with improved properties has been one of the primary challenges in a number of industrial applications. To achieve this goal, researchers implemented cost-effective processing methods and developed novel material systems

\footnotetext{
* Corresponding author: vlad.n1991@gmail.com
} 
involving low-cost fillers. One such material system is the so-called polymer concrete, which is often prepared by loading polyester resin with high levels of fillers such as fine sand, limestone or micro-marble particles (referred to as marble dust) [10,11].

Utilization of fly ash as a filler in polymer composites has received increased attention recently, particularly for price-driven/high volume applications. Incorporation of fly ash offers several advantages: it is the best way of disposing of fly ash, and as it is cheap and plentifully available, it decreases the overall cost of composites [6, 11-14]. Fly ash from thermal power plants is one of the major polluting byproducts. Its applicability is being studied extensively in various products, but with limited avenues for its reuse. As a result, it has been accumulated over the years in the surrounding areas of thermal power plants, and has created an enormous environmental problem [1].

Fly ash is used as a source of spherical fillers. As it is collected at the power plant, fly ash is a crude mixture of large and small particles of various shapes and structures. Fly ash has been reported to be a useful filler in resin systems, including phenolics, PVC, polyethylene, epoxy and polyester [15]. A composite material and method are described wherein melted waste, chemically unmodified PET material and fly ash particles are mixed in a vessel to disperse fly ash particles in the melted PET material. The resulting mixture then is cooled to solidify the melted PET material to form a polymer composite material (PCM) having a matrix comprising PET and dispersoids distributed in the matrix and comprising fly ash particles [5].

However fly ash being generated as a waste material, it needs to be benefitted before its use as filler in plastic materials. The main drawbacks of fly ash in comparison with commercial mineral fillers are its larger particle size and smooth spherical inert surface [16]. Poor adhesion does not allow the transfer of stress from the matrix to the fillers [17]. Some studies have pointed to the excellent compatibility between fly ash and polymers. Other researches have also shown the advantageous use of treated fly ash in a wide variety of polymer matrices [11].

It was found that the waste may create negative impact on some strength characteristics of the resultant composites, most likely because of poor adhesion on the "polymer/filler" interface borderline [16]. The main obstacle for utilizing fly ash in PMCs has been its surface polarity due to the presence of silanol, aluminol and other types of -OH groups attached to the metal/non-metal atoms of the constituents of fly ash. Many of the commercial polymers do not have substantial polarity that can match with that of the fly ash particles. This difficulty can be overcome by modifying the surface by suitable chemical reagents that are known as coupling agents [18]. For example, one can choose from a variety of organosilanes or titanates [19]. Addition of fly ash as filler into the polyphenylene oxide with coupling agent increased the mechanical properties such as tensile strength, impact strength, elongation at break, flexural strength and flexural modulus as compare to untreated filler filled PPO composite [12]. The good adhesion between filler (geopolymer concrete waste) and polymer was observed in the treated composites, what can be attributed to presence of oleic acid arrested onto the filler surface [20]. Fly ash with activated nano-surface (by alkali treatment - $\mathrm{NaOH}$ solution $2 \mathrm{~mol} / \mathrm{l}$ ) proved to develop uniform interfaces, with significant effect on the compression resistance and on impact [21]. Treatment of fly ash with sulfuric acid can obviously change the surface area, microstructure and phase composition [22]. Besides, it has been reported that the surface silanol groups responsible for generating Bronsted acidity are enhanced [23].

Usually, fly ash has a negative surface charge due to the predominant oxidic composition. A significant problem is that the ionic fly ash surface has a high wetting behavior, while rubber (and plastics) is hydrophobic, with very low surface charge. Therefore, building up interfaces based on electrostatic attraction is highly unlikely [21]. 
It is known that the formation of interphase bonds is affected by acid-base interactions [24]. According to [25] the strongest interphase interaction is achieved when one of the materials has the acid properties, and the other - the basic one. Accordingly, if both phases have exclusively basic or acid groups or both are neutral, then acid-base interactions are absent. Therefore, the primary task for achieving high adhesion is to determine the acid and basic characteristics of the surface of the filler and matrix.

To analyze the adhesion of polymer to filler, it is advisable to use the thermodynamic work of adhesion. The values of surface free energy (SFE) of components are necessary to calculate the thermodynamic work of adhesion $W_{a}$ between phases of PCM. According to van Oss, Chaudhury, and Good [26, 27] SFE consists of two components: the Lifshitz-van der Waals component $\left(\gamma^{W W}\right)$, and the acid-base component $\left(\gamma^{A B}\right)$. The last component is considered to be equal, $\gamma^{A B}=2 \sqrt{\gamma^{+} \gamma^{-}}$, where $\gamma^{+}$and $\gamma$ are the acidic and basic components respectively. As a result, the following relationship was formulated:

$$
W_{a}=\gamma_{L}(\cos \theta+1)=2\left(\sqrt{\gamma_{S}^{L W} \gamma_{L}^{L W}}+\sqrt{\gamma_{S}^{+} \gamma_{L}^{-}}+\sqrt{\gamma_{S}^{-} \gamma_{L}^{+}}\right)
$$

where $\gamma_{L}, \gamma_{L}^{L W}, \gamma_{L}^{+}, \gamma_{L}^{-}$- the components of the SFE for test liquids, $\gamma_{S}^{L W}, \gamma_{S}^{+}, \gamma_{S}^{-}-$the components of the SFE for solid samples, $\cos \theta$ - contact angle of sample surfaces wetting by test liquid.

Thus the acidic-basic properties of the fly ash surface can be affected through the chemical modification using acid threating method. Sulfuric acid solution with different concentration was used for threating which may bring about some strong chemical bond between filler and matrix.

The purpose of this study was to develop the composite material based on the polyethylene terephthalate polymer and pulverized fly ash, modified and unmodified with sulfuric acid.

\section{Materials and Methods}

\subsection{Materials}

Class F fly ash filler used with bulk density $1156 \mathrm{~kg} \cdot \mathrm{m}^{-3}$ was obtained from thermal power plant (Donetsk region). The particle size distribution of fly ash was determined by the ANALYSETTE 22 Compact laser diffraction particle size analyzer (Fig. 1). The particle size was mainly in the range of 5-10, 10-20, 20-30 and 30-40 $\mu \mathrm{m}$. Specific surface area is about $320 \mathrm{~m}^{2} \cdot \mathrm{kg}^{-1}$.

The composition of chemical elements and oxides was analyzed by using wavelength dispersive X-ray fluorescence method (spectrometer ARL OPTIM'X 200). The main constituents are silica, alumina and ferric oxides of about 57, 25 and 9\%, respectively, while traces of other oxides (chiefly $3.1 \% \mathrm{~K}_{2} \mathrm{O}, 1.8 \% \mathrm{CaO}, 1.5 \% \mathrm{MgO}$ and $1.05 \% \mathrm{TiO}_{2}$ ) are also noticed (Table 1). 


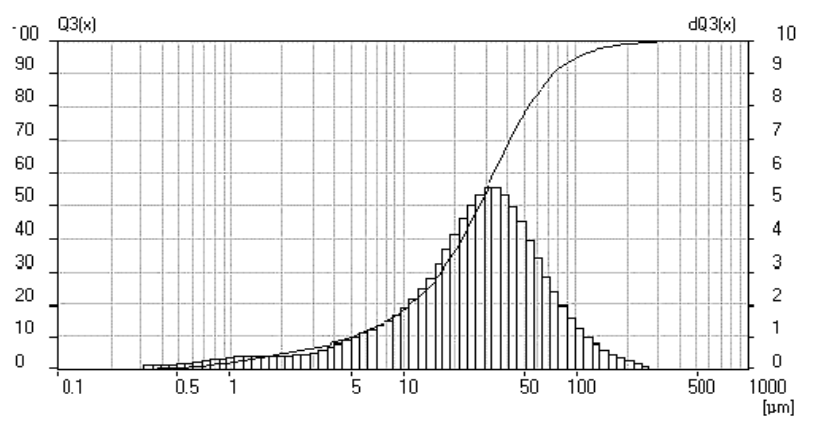

Fig. 1. Integral and differential particle size distribution of fly ash sample

Table 1. Chemical composition of the fly ash used

\begin{tabular}{|c|c|c|c|}
\hline Element & Content, \% & Oxide & Content, \% \\
\hline $\mathrm{Si}$ & 26.74 & $\mathrm{SiO}_{2}$ & 57.19 \\
\hline $\mathrm{Al}$ & 13.26 & $\mathrm{Al}_{2} \mathrm{O}_{3}$ & 25.05 \\
\hline $\mathrm{Fe}$ & 6.25 & $\mathrm{Fe}_{2} \mathrm{O}_{3}$ & 8.94 \\
\hline $\mathrm{K}$ & 2.57 & $\mathrm{~K}_{2} \mathrm{O}$ & 3.09 \\
\hline $\mathrm{Ca}$ & 1.28 & $\mathrm{CaO}$ & 1.79 \\
\hline $\mathrm{Mg}$ & 0.88 & $\mathrm{MgO}$ & 1.45 \\
\hline $\mathrm{Ti}$ & 0.63 & $\mathrm{TiO}_{2}$ & 1.05 \\
\hline
\end{tabular}

The PET bottles prepared for processing by first rinsing in warm water to remove any residue. Next, the bottle caps, labels and adhesives were physically removed. Once washed and air-dried, the PET bottles were shredded to nominal square particle sizes of 5 to $15 \mathrm{~mm}$ using a knife crusher.

\subsection{Processing}

Modification of the filler surface was carried out with solutions of sulfuric acid $\left(\mathrm{H}_{2} \mathrm{SO}_{4}\right)$ with different concentrations $(5,10$, and $15 \%)$. Samples of the fly ash were placed into acid solution for about 1 hour then were dried to constant weight at a temperature of $105-110^{\circ} \mathrm{C}$.

The fly ash filler and PET flakes were dried at a temperature of $105-110^{\circ} \mathrm{C}$ to reduce their moisture content before preparation of PCM samples. Samples of PCM were made by injection molding at a temperature of $250-280^{\circ} \mathrm{C}$.

Melted waste PET material and fly ash particles were mixed in a vessel to disperse fly ash particles in the melted PET material. Samples of PCM were made by injection molding at a temperature of $250-280^{\circ} \mathrm{C}$. After the molding process the samples were cooled to solidify the melted PET material to form a composite material having a matrix comprising PET and dispersoids distributed in the matrix and comprising fly ash particles [5]. The PCM samples were prepared on the base of formulations with different content (55-75 wt.\%) of unmodified and modified filler.

\subsection{Methods}

Compressive strength was tested according to ASTM D695 using servo-hydraulic system ADVANTEST 9. Compressive properties were checked at speed of $50 \mathrm{~mm} / \mathrm{min}$. Load cell of $5 \mathrm{kN}$ was used to sense the load. Five specimens ( $50 \mathrm{~mm}$ cubes) of each formulation were tested and their average value was calculated. 
Density and water absorption of PCM samples were tested according to ASTM D792 and D570 respectively.

The contact angles of sample surfaces were measured with the help of tensiometer KRUSS K100 and a set of test liquids with known values of the SFE [28] included distilled water, glycerin, aniline, phenol, formamide, ethylene glycol, and dimethyl sulfoxide (Table 2). The Washburn method [29] for fly ash and Wilhelmy plate method [30] for PET samples were used to calculate contact angles of sample surfaces.

SFE components and thermodynamic work of adhesion

To determine the Lifshitz-van der Waals $\left(\gamma_{S}^{L W}\right)$, the acid $\left(\gamma_{S}^{+}\right)$and basic $\left(\gamma_{S}^{-}\right)$SFE components of the samples, a method developed by Sokorova [31] was used. It is a graphical method based on multidimensional approximation. According to this method, equation (1) transforms to the plane equation $(\mathrm{z}=\mathrm{Ax}+\mathrm{By}+\mathrm{C}:)$ :

$$
\frac{\gamma_{L}(1+\cos \theta)}{2 \sqrt{\gamma_{L}}}=\frac{\sqrt{\gamma_{L}^{L W}}}{\sqrt{\gamma_{L}^{-}}} \cdot \sqrt{\gamma_{S}^{L W}}+\frac{\sqrt{\gamma_{L}^{+}}}{\sqrt{\gamma_{L}^{-}}} \cdot \sqrt{\gamma_{S}^{-}}+\sqrt{\gamma_{S}^{+}}
$$

Components of the SFE for test liquids $\left(\gamma_{L}, \gamma_{L}^{L W}, \gamma_{L}^{+}, \gamma_{L}^{-}\right)$and experimentally measured the values of the contact angles of sample surfaces wetting by test liquids $(\cos \theta)$ are required to calculate parameters of solid samples $\left(\gamma_{S}^{L W}, \gamma_{S}^{+}, \gamma_{S}^{-}\right)$.

Next, using a multidimensional approximation, a plane was constructed in the coordinates $\left(\frac{\sqrt{\gamma_{\mathrm{L}}^{\mathrm{LW}}}}{\sqrt{\gamma_{\mathrm{L}}^{-}}} ; \frac{\sqrt{\gamma_{\mathrm{L}}^{+}}}{\sqrt{\gamma_{\mathrm{L}}^{-}}} ; \frac{\gamma_{\mathrm{L}}(1+\cos \theta)}{2 \sqrt{\gamma_{\mathrm{L}}^{-}}}\right)$. For calculation of the coefficients $\mathrm{A}, \mathrm{B}$ and $\mathrm{C}$ for the plane equation the software StatSoft STATISTICA ${ }^{\circledR}$ was used. According to this method, the coefficient A is equal to the value of the root of the Lifshitz-van der Waals component of the SFE $\left(\sqrt{\gamma_{S}^{L W}}\right)$; coefficient B - value of the root of the basic component $\left(\sqrt{\gamma_{S}^{-}}\right)$; coefficient $\mathrm{C}$ - the value of the root of the acid component $\sqrt{\gamma_{S}^{+}}$).

Table 2. SFE parameters of test liquids

\begin{tabular}{|l|c|c|c|c|c|}
\hline Test liquid & $\begin{array}{c}\gamma_{S}^{L W}, \\
\mathrm{~mJ} \cdot \mathrm{m}^{-2}\end{array}$ & $\begin{array}{c}\gamma_{S}^{A B}, \\
\mathrm{~mJ} \cdot \mathrm{m}^{-2}\end{array}$ & $\begin{array}{c}\gamma_{S}^{+}, \\
\mathrm{mJ} \cdot \mathrm{m}^{-2}\end{array}$ & $\begin{array}{c}\gamma_{S}^{-}, \\
\mathrm{mJ} \cdot \mathrm{m}^{-2}\end{array}$ & $\begin{array}{c}\gamma_{S}, \\
\mathrm{~mJ} \cdot \mathrm{m}^{-2}\end{array}$ \\
\hline Distilled water & 22.0 & 50.2 & 28.3 & 22.2 & 72.2 \\
\hline Glycerol & 33.9 & 29.8 & 32.7 & 6.8 & 63.7 \\
\hline Aniline & 41.2 & 2.0 & 0.2 & 5.7 & 43.2 \\
\hline Formamide & 31.8 & 25.7 & 5.2 & 32.4 & 57.5 \\
\hline Ethylene glycol & 29.0 & 19.0 & 12.1 & 7.5 & 48.0 \\
\hline Dimethyl sulfoxide & 34.9 & 8.7 & 2.1 & 9.1 & 43.6 \\
\hline
\end{tabular}

\section{Results and discussion}

SFE components for PET, unmodified fly ash and modified fly ash (treated with 5 and $10 \%$ concentration solution of sulfuric acid) were calculated (Table 3). The resulting graphs and equations are shown on figures 2-5.

It was established that sulfuric acid treatment affects the filler surface SFE components. When fly ash was treated with $5 \%$ solution $\mathrm{H}_{2} \mathrm{SO}_{4}$, the components of $\mathrm{SFE}\left(\gamma_{S}^{+}\right)$and $\left(\gamma_{S}^{-}\right)$were increased in comparison to unmodified fly ash on $43.1 \%$ and $7.7 \%$, respectively. And when 
fly ash was treated with $10 \%$ solution $\mathrm{H}_{2} \mathrm{SO}_{4}$, the components of SFE $\left(\gamma_{S}^{+}\right)$and $\left(\gamma_{S}^{-}\right)$were increased on $89.3 \%$ and $14.5 \%$, respectively.

Table 3. SFE parameters of PET, unmodified and modified fly ash

\begin{tabular}{|l|c|c|c|c|c|}
\hline \multicolumn{1}{|c|}{ Material } & $\begin{array}{c}\gamma_{S}^{L W}, \\
\mathrm{~mJ} \cdot \mathrm{m}^{-2}\end{array}$ & $\begin{array}{c}\gamma_{S}^{A B}, \\
\mathrm{~mJ} \cdot \mathrm{m}^{-2}\end{array}$ & $\begin{array}{c}\gamma_{S}^{+}, \\
\mathrm{mJ} \cdot \mathrm{m}^{-2}\end{array}$ & $\begin{array}{c}\gamma_{S}^{-}, \\
\mathrm{mJ} \cdot \mathrm{m}^{-2}\end{array}$ & $\begin{array}{c}\gamma_{S}, \\
\mathrm{~mJ} \cdot \mathrm{m}^{-2}\end{array}$ \\
\hline PET & 35.0 & 0.07 & 3.0 & 3.5 & 38.5 \\
\hline FA unmodified & 22.0 & 9.5 & 5.2 & 7.7 & 29.7 \\
\hline $\begin{array}{l}\text { FA modified with 5\% acid } \\
\text { solution }\end{array}$ & 21.9 & 13.6 & 5.6 & 8.8 & 30.7 \\
\hline $\begin{array}{l}\text { FA modified with 10\% acid } \\
\text { solution }\end{array}$ & 19.9 & 18.0 & 5.9 & 9.8 & 29.8 \\
\hline
\end{tabular}

On the base of these data the thermodynamic work of adhesion between PET and fly ash filler was calculated in accordance with equation (1) (Table 4). It was established that the thermodynamic work of adhesion between PET polymer and modified fly ash filler with 5\% and $10 \%$ solution of acid was increased on $1.29 \%$ and $2.14 \%$, respectively.

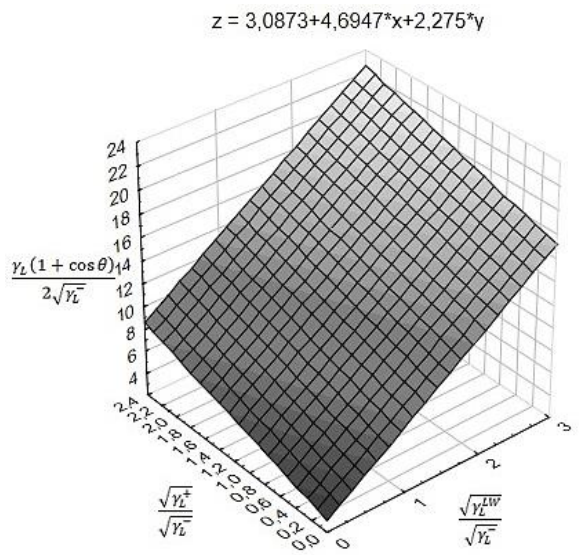

Fig. 2. The surface graph and the equation of the plane for unmodified FA

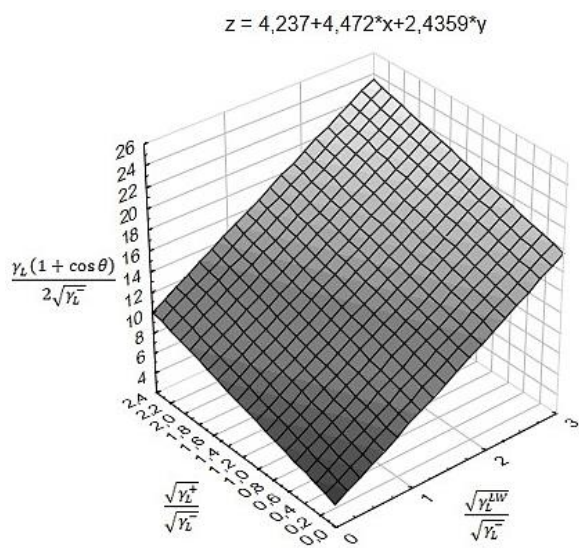

Fig. 4. The surface graph and the equation of the plane for FA treated with $10 \%$ acid solution

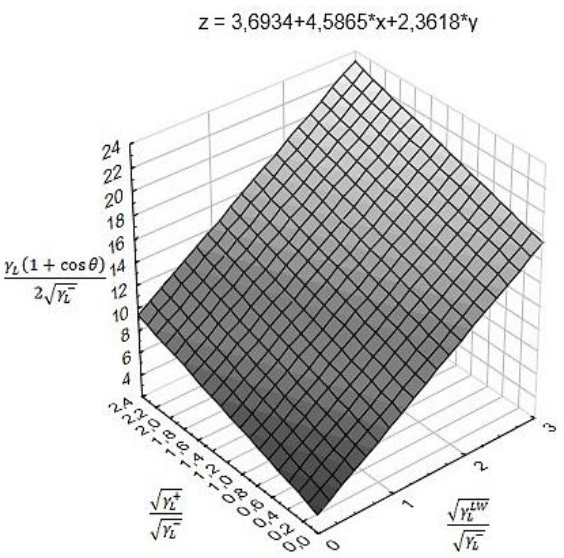

Fig. 3. The surface graph and the equation of the plane for FA treated with 5\% acid solution

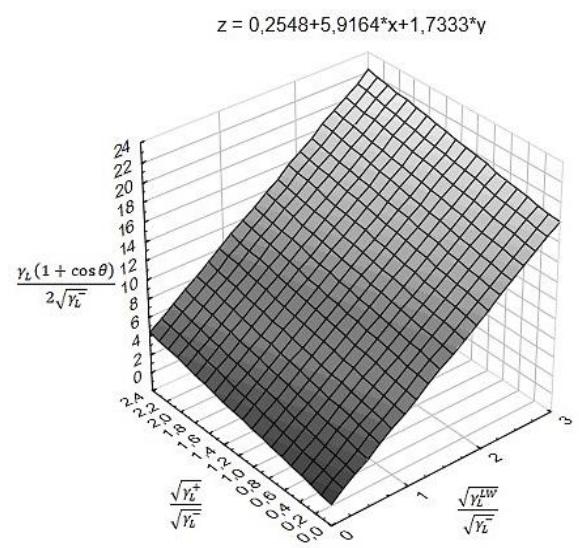

Fig. 5. The surface graph and the equation of the plane for PET 
Table 4. Thermodynamic work of adhesion between PCM components

\begin{tabular}{|c|l|c|}
\hline Matrix & \multicolumn{1}{|c|}{ Filler } & $\mathrm{W}_{\mathrm{a}}, \mathrm{mJ} \cdot \mathrm{m}^{-2}$ \\
\hline \multirow{3}{*}{ PET } & FA unmodified & 67.41 \\
\cline { 2 - 3 } & FA modified with 5\% acid solution & 68.28 \\
\cline { 2 - 3 } & FA modified with 10\% acid solution & 68.85 \\
\hline
\end{tabular}

To confirm increasing adhesion between the polymeric matrix and modified fly ash filler compressive strength of PCM samples with different filler concentration was tested (Fig. 6). The highest value of compressive strength of samples with unmodified fly ash filler has PCM with $65 \%$ filler concentration. On the other hand when fly ash filler was modified with $5 \%$ concentration solution $\mathrm{H}_{2} \mathrm{SO}_{4}$ compressive strength of PCM sample was higher on $11.2 \%$. So this phenomena may confirm increasing adhesion acid/basic interaction between PCM components.

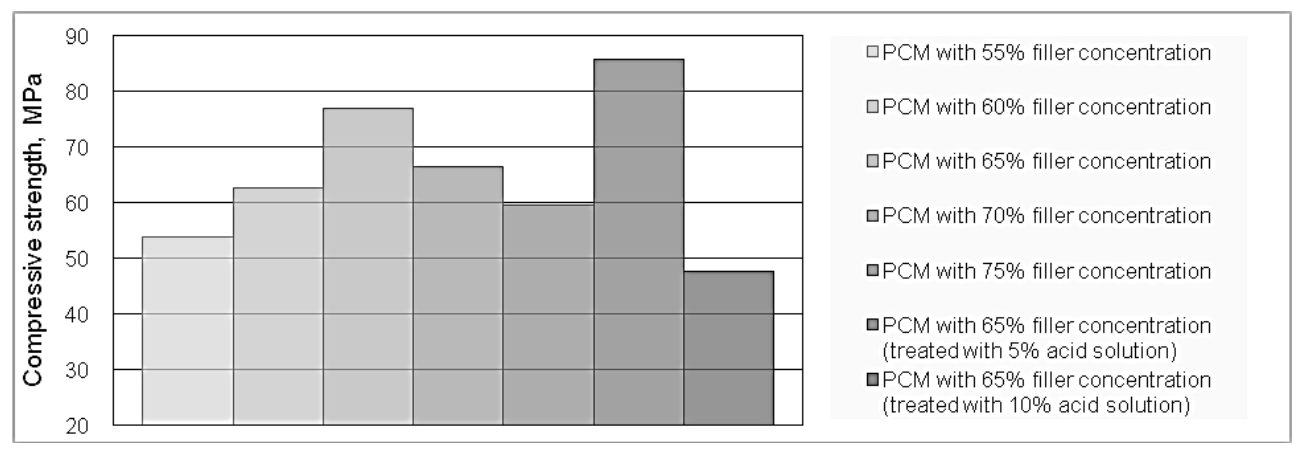

Fig. 6. Compressive strength of PCM samples

However, the samples containing $65 \%$ fly ash filler treated with $10 \%$ concentration solution of acid demonstrated lower results despite the higher thermodynamic work of adhesion. It is presumably because of the increase weak sulphuric formations $\left(\mathrm{SO}_{3}\right)$ on the filler surface after treatment which impedes the adhesion contact of components.

Table 5 presents the main properties of PCM with optimal formulation.

Table 5. Properties of PCM with optimal formulation

\begin{tabular}{|l|c|}
\hline Property & Value \\
\hline Filler concentration, \% & 65 \\
\hline Compressive strength, MPa & 85.7 \\
\hline Density, $\mathrm{kg} \cdot \mathrm{m}^{-3}$ & 1722 \\
\hline Water absorption (48 hours), \% & 0.17 \\
\hline
\end{tabular}

\section{Conclusions}

Sulfuric acid treatment affects the filler surface SFE components. When fly ash was treated with $5 \%$ solution $\mathrm{H}_{2} \mathrm{SO}_{4}$, the components of SFE $\left(\gamma_{S}^{+}\right)$and $\left(\gamma_{S}^{-}\right)$were increased in comparison to unmodified fly ash on $43.1 \%$ and $7.7 \%$, respectively. When fly ash was treated with $10 \%$ solution $\mathrm{H}_{2} \mathrm{SO}_{4}$, the components of SFE $\left(\gamma_{S}^{+}\right)$and $\left(\gamma_{S}^{-}\right)$were increased on $89.3 \%$ and $14.5 \%$, respectively. The thermodynamic work of adhesion between PET polymer and modified fly ash filler with $5 \%$ and $10 \%$ solution of acid was increased on $1.29 \%$ and $2.14 \%$, respectively. Treatment of fly ash filler to improve its adhesion characteristics to the PET polymeric matrix improves the overall properties of the PCM, especially compressive strength and density. The highest value of compressive strength of samples with unmodified fly ash filler has PCM 
with $65 \%$ filler concentration. On the other hand when fly ash filler was modified with $5 \%$ concentration solution $\mathrm{H}_{2} \mathrm{SO}_{4}$ compressive strength of PCM sample was higher on $11.2 \%$.

The reported study was funded by the Center of shared usage of equipment NRU MGSU (Moscow).

\section{References}

1. M. Dasgupta, S. Kar, S. Das Gupta, R. Mukhopadhyay, and A. Bandyopadhyay, Progr in Rubber, Plast and Recyc Tech, 29 (3), 151-168 (2013).

2. L.I. Ogorodov, and O.V. Lustina, Mag. Civ..Eng., 6 (74), 17-32 (2017).

3. A.N. Ponomarev, and A.S. Rassokhin, Mag. Civ..Eng., 8 (68), $45-57$ (2016).

4. C. Chen, C.M. Wu, F.C. Pu, C.H. Chiu, eXPRESS Polym Letters, 5 (3), 228-237 (2011).

5. Y. Li, R.L. Peyton, and D.J. White, Iowa State University Patents US 6,583,217 B1 (2003).

6. R.S.N. Sahai, and P.A. Mahanwar, Int J Chem, Envir \& Biol Sci, 3 (2), 164-168 (2015).

7. F.C. Campbell, Struct Comp Mater (2010).

8. E.A. Nekliudova, A.S. Semenov, B.E. Melnikov, and S.G. Semenov, Mag. Civ..Eng., 3 (47), 25-39 (2014).

9. M.G. Icduygu, L. Aktas, and M.C. Altan, Polym \& Polym Comp, 21 (3), 171-176 (2013).

10. D.A. Vakulenko, and R.A. Turusov, Mag. Civ..Eng., 7 (75), 106-113 (2017).

11. I. Ahmad, and P.A. Mahanwar, J Miner \& Mater Charact \& Eng, 9 (3), 183-198 (2010).

12. R.S.N. Sahai, and N. Pawar, Int J Chem, Environ \& Biol Sci, 2 (4), 187-192 (2014).

13. Kishore, S.M. Kulkarni, D. Sunil, and S. Sharathchandra, Polym Int, 51, 1378-1384 (2002).

14. M.S. Sreekanth, V.A. Bambole, S.T. Mhaske, and P.A. Mahanwar, J Miner \& Mater Charact \& Eng, 8 (3), 237-248 (2009).

15. N. Chand, J Mater Sci Let, 7, 36-38 (1988).

16. S. Bonda, S. Mohanty, and S.K. Nayak, Mater Express, 4 (5), 384-392 (2014).

17. Joy Erika P. Reyes, Int J Chem Eng Applic, 6 (1), 6-11 (2015).

18. S. Guhanathan, M.S. Devi, and V. Murugesan, J Appl Polym Sci, 82, 1755-1760 (2001).

19. S. Anandhan, Int J Waste Res, 4 (3) (2014).

20. A.P. dos Santos Pereira, M.H.P. da Silva, É.P.L. Júnior, A. dos Santos Paula, and F.J. Tommasini, Mater Res, 20 (2), 411-420 (2017).

21. A. Duta, C. Cazan, and M. Cosnita, World of Coal Ash (WOCA) Conf, CO, USA (2011). 22. M. Qiu, Y. Wang, M. Niu, Q. Han, and M. Zhang, Amer Chem Sci J, 14 (4), 1-6 (2016). 23. A. Sharma, K. Srivastava, V. Devra, and A. Rani, Amer Chem Sci J, 2 (4), 177-187 (2012).

24. A.J. Kinloch, Adhesion and adhesives, Sci and tech (1991).

25. C.J. van Oss, M.K. Chaudhury, and R.J. Good, Separation Sci Tech, 24 (1-2), 15-30 (1989).

26. C.J. van Oss, R.J. Good, and M.K. Chaudhury, J Col Int Sci, 111 (2), 378-390 (1986).

27. C.J. van Oss, M.K. Chaudhury, and R.J. Good, Chem Rev, 88 (6), 927-940 (1988).

28. N. Dyk An, PhD dissertation (Chemistry), Kazan National Research Technological University (2016). 
29. E.W. Washburn, Physical Rev, 17 (3), 273-283 (1921).

30. K. Holmberg, Handbook of Applied Surface and Colloid Chemistry, New York, Wiley and Sons, 2 (2002).

31. N.V. Sokorova, PhD dissertation (Chemistry), Kazan National Research Technological University (2011). 